\title{
The Mo.N.G.U.E. Development and Experimentation Project in Mozambique
}

\author{
Liala Baiardi
}

\begin{abstract}
The Development and Experimentation project in Mozambique led to the elaboration of a model and an investigation process aimed at delineating a cognitive base useful to trace possible improvement actions to be undertaken while respecting the preservation of the place's identity in accordance with developmental continuity. The project is located in a territorial context of great natural value which is being restored as a social and identity point of reference. For this reason, it needs protection from uncontrolled urban growth that could undermine the community-environment system. The general objective is to make Mongue a place with a recognisable identity for a large community through shared interdisciplinary planning aimed at establishing a plurality of functions and services. The aim is to create a new system capable of feeding that rooting in the place, necessary to counter the tendency to eradicate local populations.
\end{abstract}

Keywords Process approach $\cdot$ Development $\cdot$ Sustainability $\cdot$ Feasibility Interdisciplinarity

\section{Introduction}

The transformation process which is going through Africa is also highlighted by the significant increase in the urbanisation rate, which has risen from $15 \%$ in 1960 to $40 \%$ in 2010 (UN-Habitat 2015). It can be seen that the population in Mozambique has increased from 5 to 25 million inhabitants in the last century. A strong indicator of this rapid growth is that $45 \%$ of the population in 2015 was younger than 14 years (Instituto Nacional de Estatística 2015). The significant increase in population has generated critical issues related to fast urbanisation, the depletion of environmental resources and the wealth of local cultures. The consequences are, for instance, poor quality living spaces and housing facilities, lack of places for social gatherings and

\footnotetext{
L. Baiardi $(\varangle)$

Architecture, Built Environment and Construction Engineering-ABC Department, Politecnico di Milano, Milan, Italy

e-mail: liala.baiardi@polimi.it 


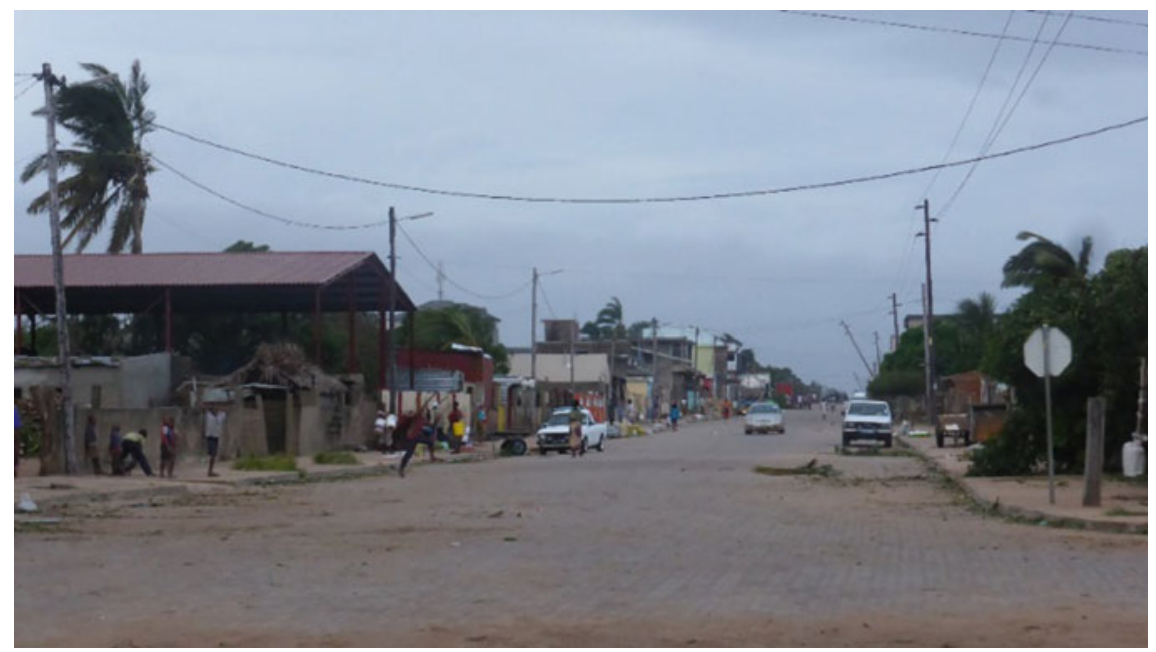

Fig. 1 Town of Maxixe (author's photo)

educational facilities for children and serious problems concerning the safety and hygiene of places and people.

As already highlighted by previous studies (Monga and Lin 2015; Scott 2015), it is considered impossible to overcome poverty or the growth challenge in Africa without considering the importance of urbanisation.

The poor construction quality of the buildings and the limited application of maintenance actions, together with the lack of spatial regulations to support the strategic planning of the territory's development, significantly reduce the capacity of the system to resist climatic variations, to adapt to the effects of disorder and to regenerate following change whilst preserving its functions and identities.

The development practice of the Mozambican territory is predominantly characterised by the lack of an interdisciplinary design methodology applied to the reading and the design of places, capable of enhancing the area with its natural and social landscapes, its historical and architectural heritage, space liveability and environmental sustainability aspects. In this context, the Mongue Development and Experimentation Project is proposed with the aim of helping to bridge the design methodology gap that characterises many interventions in these areas, which are often the result of the generous but sometimes confused spontaneity of international social actors or their lack of knowledge/experience (Fig. 1).

\section{Territorial Framework}

Between 1498 and 1975, Mozambique was a Portuguese colony. The country gained its freedom after a decade of guerrilla warfare (Thompson 2013). Only one year after its independence from Portugal, a rebel group called Resistência Nacional Moçambicana (RENAMO) opposed the liberation movement generating a series of internal 
uprisings that lasted until 1992. The number of victims of this internal struggle is estimated at between 600,000 and 1 million people (World Peace Foundation 2015). The country, which was already in a state of poverty, found itself in an even worse situation.

The situation has improved in recent years: according to a national survey, the number of Mozambicans living in absolute poverty has been reduced from $70 \%$ (in 1997) to 54\% (in 2008-2009). However, most of the rural population still lives on less than $\$ 1.25$ a day and lacks basic services such as safe access to water, sanitation and schooling (IFAD 2014).

Surveys carried out on the country's development between 2000 and 2005 (Ollivier and Giraud 2011) highlight that the wealth of Mozambique has increased mainly through the accumulation of human and physical capital, while pressure on renewable natural capital remains relatively low. Although in the past, there was an average annual growth of 7\% in GDP (Gross Domestic Product), it is expected that by 2040, there will be 18.7 million people living in absolute poverty, which is almost the same as today (19 million) (Porter et al. 2018).

The rapid and uncontrolled urbanisation (IHS 2017) spreading across the country favours the creation of shanty towns: in 2009, around $80 \%$ of the urban population lived in impoverished districts (WHO 2014).

The government is actively fighting the country's main problems. Some examples include the WASH project (water, sanitation and hygiene) promoted by UNICEF for access to safe water, sanitation and hygiene, and the PARPA project 'Action Programme to Reduce Extreme Poverty' developed by the Ministry of Planning and Development of Mozambique (IMF 2011) (Figs. 2 and 3).

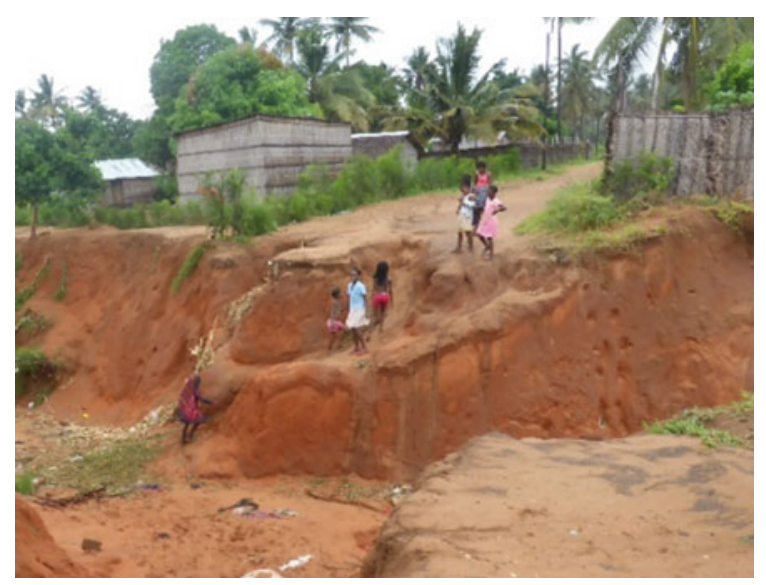

Fig. 2 Example of the harmful effects of uncontrolled urbanisation. Episodes of soil erosion due to torrential rains in a typical shanty town in the village of Maxixe (author's photos) 


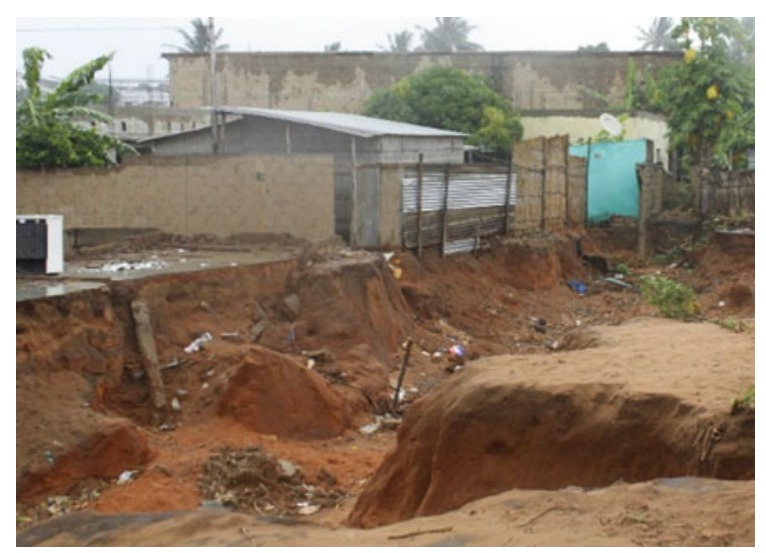

Fig. 3 Example of the harmful effects of uncontrolled urbanisation. Episodes of soil erosion due to torrential rains in a typical shanty town in the village of Maxixe (author's photos)

\section{The Mo.N.G.U.E. Mozambique Project. Nature. Growth. University. Education}

The heading, a play on words on the name of the town 'Mongue' (a town in Mozambique), aims to bring to light certain general objectives that are considered important for the reference context:

- The big theme of nature, the environment and landscape and its hazardous condition and potential;

- The unique theme of growth primarily understood as development in a qualitative and sustainable sense;

- The university as a major driving force of economic, but above all, civil development in the country;

- The grounds for widespread education, education for all, which now also extends to nursery.

The research proposal, selected from among the winners of the Politecnico di Milano 'Polisocial Award' (2016 edition), ${ }^{1}$ relates to the local authorities' support in safeguarding the landscaping of the territory. It proposes the creation of a protected area by establishing the Ecological Park at the University of Pedagogy in Maxixe.

The research involves an application-oriented testing activity on a project to test a methodology replicable in similar contexts. The aim is not to define prefabricated modules that can be assembled and reassembled again in an undifferentiated manner,

\footnotetext{
${ }^{1}$ Politecnico di Milano working group: Liala Baiardi, Michele Ugolini, Valentina Dessi, Rossana Gabaglio, Laura Montedoro, Lorenza Petrini, Stefania Varvaro, Luca Faverio, Filippo Ganassini and Marco Talliani.
} 
isolated from the context and environment in which they are placed, but rather to develop a useful method in a conscious design practice with new interventions: an interdisciplinary working path (mapping, analysis, strategies, methods, projects, etc.) capable of interpreting the demand for improving people's living conditions (quality and livability of spaces and the environment with a view to environmental sustainability).

\section{Development Methodology}

The research led to the development of a model and a process of inquiry aimed at outlining the state of affairs and suggesting possible improvement to be attained as regards preservation of the place's identity according to a developmental continuity.

The experimental aspect has allowed for the model to be refined (application phase) directly in the field, resulting in inspections being scheduled within the context of Mozambique as a reference point.

Mongue was identified as an area of study and experimentation during the application phase: it is a peninsula that stretches for about $20 \mathrm{~km}$ north of the town of Maxixe. The peninsula is of particular interest, as it contains certain rural context phenomena (spatial neglect, lack of care for the environment, etc...), and at the same time, it risks suffering the effects of the settlement tensions that characterise the peripheral areas of the urbanised cities. This place is also full of identity and history in that, in addition to the rare presence of buildings dating back to the period of the Portuguese colonisation, the first missionary home was built there in southern Mozambique and abandoned during the Revolution and the Civil War (1964-92) (Fig. 4).

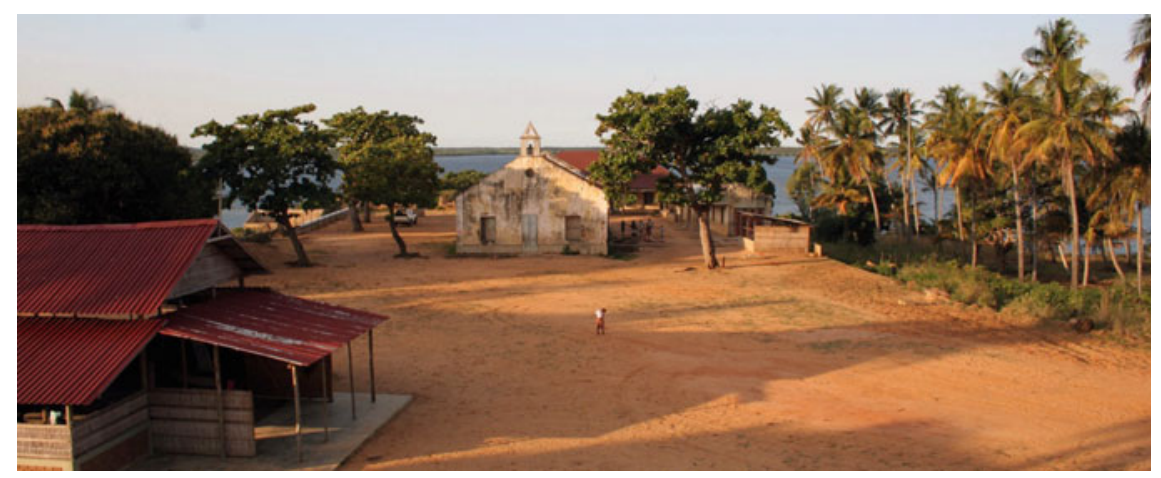

Fig. 4 Mongue mission (author's photo) 
The scheduling of the screening process resulted in the planning and processing phases of the work summarised as follows: the development of relations with public institutions, residents and local professionals; multidisciplinary thematic mapping and analytic interpretation; definition of a framework of levels and indicators to define qualitative and quantitative metrics; definition of an intervention strategy for the study area through an interdisciplinary design method.

The working hypothesis is necessarily based on multidisciplinary assumptions that define the different levels of the project in order to achieve a common goal (interdisciplinary). The areas of competence put in place to fulfil the various analytical and design aspects highlight the multidisciplinary nature of the project:

- Architectural, interior and open spaces, urban, regional and landscape;

- Preservation of historic buildings and existing buildings; structural-technical and bioclimatic, environmental and energy sustainability;

- Economic enhancement, financial sustainability (Monti and Romano 2010), management and building maintenance.

The added value of this multidisciplinary approach lies in making operational syntheses to overcome dystonias arising from mono-disciplinary approaches (the latter, in fact, have the limitation of not considering the complexity of the problems that affect the spaces of our lifestyles at all levels). This requires a careful approach to local resources/conditions that will define a framework of useful levels and indicators to clarify the qualitative and quantitative metrics identified as follows:

- Usage patterns of public and living spaces;

- Analysis of materials and traditional construction techniques;

- Analysis of the bioclimatic and environmental conditions;

- Analysis of local energy systems/water supply production;

- Acquisition of historical and socio-cultural knowledge.

The added value of the identified methodology is also given by the synergy between the skills of the Politecnico's applicants with the different local knowledge: advanced training from the Pedagogical University; the knowledge gained in the field by the missionaries from the Sagrada Familia; the needs expressed by local communities (Fig. 5).

\section{Results}

With the proposal to establish a park and a research centre, the aim is to sustainably design spaces adapted to territorial needs and local communities, by way of strengthening the services offered, creating a socialisation process aimed at physically transforming places, and making room for better living conditions. 


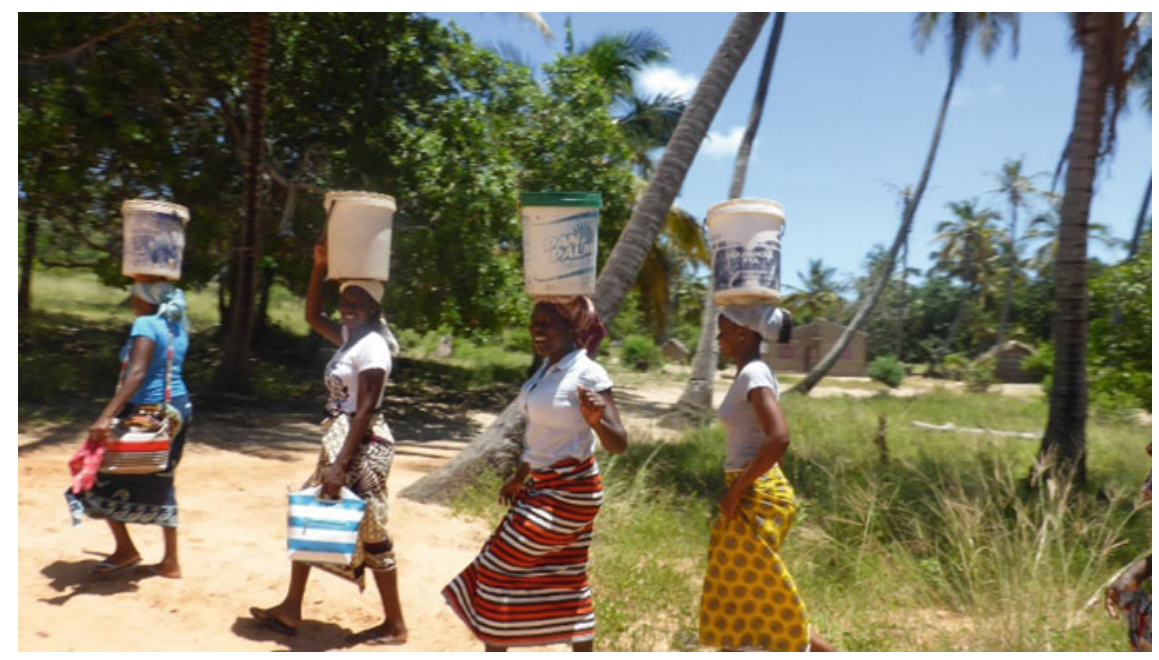

Fig. 5 The water supply ritual. The Mongue area only has one single distribution point for drinking water, and there is no water distribution network to homes (author's photo)

Using an analytical-interpretative approach, focused on the specificity of the places and the social problems, the research project paid close attention to the natural, environmental, landscape, architectural and social resources in the area. This aims to bridge the design methodological gap that has characterised some interventions made by Western operators in the context of developing countries, sometimes with high architectural and performance qualities but substantially unrepeatable and which, beyond the intervention itself, do not leave any methodological seeds for future developments in the area (Fig. 6).

The research activity led to the development of a master plan which, in addition to the relationship between the buildings, also takes into appropriate consideration the system of liveable and vital open spaces, with the ability to attract the local community and create a sense of affiliation to the place. The next step concerns the building design, focusing in particular on the internal distribution of the premises in order to provide the best living conditions that can optimise the use of materials and energy resources available in the area and ensure the best hygiene and thermohygrometric comfort conditions.

'Data' on the effectiveness of the design are also evaluated through the use of quantitative indicators and qualitative parameters that were used to build a methodological analysis and therefore represent the project's fundamental footprint. The green system, the built system, the system of techniques and materials, the soil levels system, the landscape system, the connections system and the energy and bioclimatic systems must all find mutual verification. Some aspects are more easily verifiable through the use of commonly used quantitative indicators, especially for economic and energyenvironmental aspects, while other aspects related to the themes of architectural space can only be measured quantitatively in a partial and somewhat inefficient way 


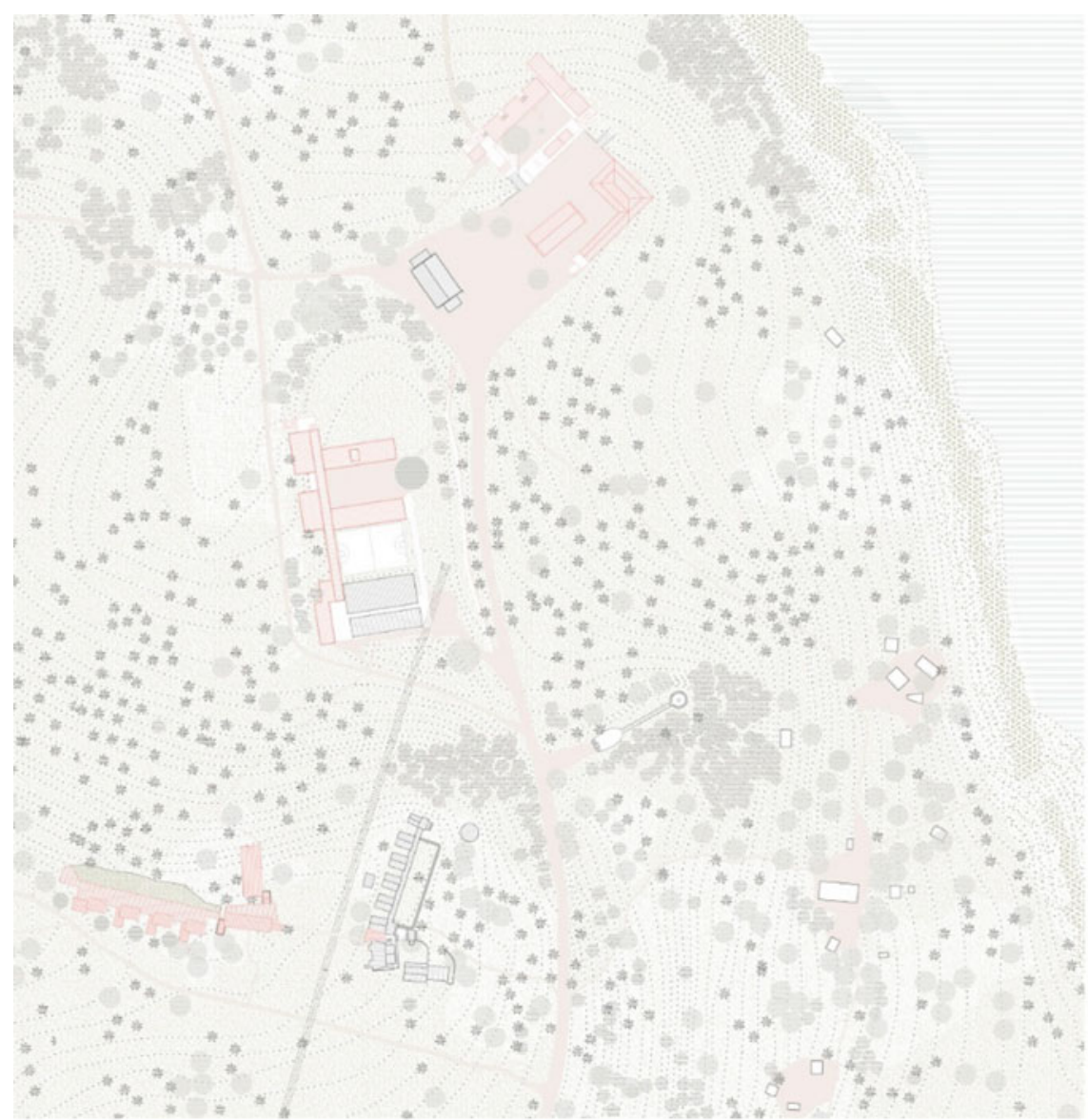

Fig. 6 Project at the Research Centre in the Mongue Park. Authors: the MoNGUE working group

(square metres, volumes, regulatory ratios, etc.). These aspects find their verification potential in another manner through graphic diagrams of comparison between the factual state and the project, 3D simulations on the design of open spaces, green areas and buildings, including the various evaluated hypotheses, photo inserts and overlapping territorial sections. Data collected on site through instrumental measurements, photographs and physical reconnaissance-interpretations serve to demonstrate the appropriateness and in-depth study of the project. Verifiable aspects through the use of quantitative indicators:

- Verification of the enhancement: areas usable for group activities and socialising; service activities for children (number of children accepted into new school facilities, increasing the useful space for children); area recovered in the historical heritage of the mission and its corresponding enhancement; accommodation capacity (number of people housed in the accommodation). 
- Project's socio-economic feasibility: number of jobs created (which helps to define the increase in financial support that local families can receive), Net Present Value (NPV, which is the discounting of all positive and negative cash flows that characterise the project), the project's Internal Rate of Return (IRR) which is useful for comparing the project's alternative hypotheses and the investment repayment periods (Payback period) representing the number of years required to repay the investment.

- Environmental performance: the evaluation of the parameters summarised in the project, linked to the orientation, the distribution of the environments, the placement of the openings and the building system, which regulate the availability of passive energy resources, is assessed through the use of a thermal comfort indicator (PMV, for example), and simultaneously the primary thermal energy demand required to meet thermal comfort conditions.

- Energy saving during the production of the materials, the construction and maintenance of buildings, for monitoring and comparing pre-variations and postinterventions with sizeable interest, such as traditional biomass savings, the efficiency of cooking systems, kWh products and those used through conventional and alternative systems, and fuel savings for the generators.

\section{Possibility for Future Developments and Weaknesses}

The expected results are to share the design methodology with local players and, thanks to close cooperation with the local university system, the training of professors and students along with a growing awareness of the local communities. Direction, in all its phases (planning, design, construction and programming), is crucial to the success of any initiative and is the fundamental basis of satisfactory management, including socio-economic, of the building and the territorial system over the years.

Adopting this approach, however, involves the effort of being able to associate the main features (uniqueness, physicality and immobility) of real estate with mathematical and financial elements.

Real estate is first and foremost a physical asset, closely related to its context, and presents unique characteristics that make it difficult to compare with other properties without using type approval parameters.

In addition to the local dimension affected by the intervention, the project has the potential to cause an impact on a larger scale, on the region or the country, where it will become known as best practice and will bring a dimension of complexity to the transformation initiative even in low-cost areas (Table 1). 
Table 1 List of the main benefits arising from the project

Benefits deriving from the project success

Social

Restoration and enhancement of the mission facilities at disposition of local people: school, canteen and church

Creation of 17 new job positions during the whole year

Possible improvement of general conditions of the surrounding area

Improvement of the services present in the area

Possible improvement of the infrastructure system connecting Mongue with Maxixe

Introduction of an electricity system

Creation of a reference point for local population

Creation of an international educational meeting point

Creation of an exchange of information and resources network between universities

Collaboration with other facilities in the area or acquisition of external services from the community

Construction of a small dock that will connect Mongue directly to Inhambane and to their villages across the river

\section{Environment}

Encourage the creation of the Municipal Ecological Park of Maxixe, a project proposal made by the Universidade Pedagógica-Maxixe

Constant monitoring of the environment guarantees a prompt reaction to new arising issues

Protection of flora and fauna in the area surrounding the research center

Monitoring of the bay ecosystem and protection from excessive fishery and use of illegal methods (e.g. explosive)

Introduction of sustainable source of energy and of an electricity system that will lower the increasing use of wood as the main source of energy

Economic

Introduction of a new economic activity in the area

Yearly average profit coming from rent and other services offered during the touristic season is estimated to be around $€ 90,000$

The initial investment is expected to be recovered in less than 5 years and 6 months

During the calculation of the investment Net Present Value, the use of a discount rate smaller than $14.69 \%$ resulted in a positive outcome of the analysis

The underlying hypothesis of being inside a natural reserve guarantees a donation equal to $€ 20,000$ to support local communities

Exploitation of every period of the year, maximising the use of the receptive structure

Authors: L. Baiardi, M. Talliani 
Acknowledgements The Mo.N.G.U.E. project is funded by the Polisocial Program and is carried out jointly with the 'Pedagógica Universidade de Moçambique, Delegação de Maxixe-UniSaF and The Sagrada Familia Congregation. The following are supporters with a declared interest: Pedagógica the Universidade de Moçambique, the town of Maxixe, the Diocese of Inhambane, the Italian Embassy in Maputo.

\section{References}

IFAD (International Fund for Agricultural Development) (2014) Investing in rural people in Mozambique. https://www.ifad.org/documents/10180/bf1817c4-7061-40d6-9291-4512691f15fd

IHS (Institute for Housing and Urban Development Studies) (2017) Urbanization in Mozambiqueassessing actors, processes, and impacts of urban growth. http:/www.citiesalliance.org/sites/ citiesalliance.org/files/Urbanization\%20in\%20Mozambique.pdf

Instituto Nacional de Estatística (2015) Anuário Estatístico 2015 - Moçambique. Instituto Nacional de Estatística, Maputo, Mozambique

Monga C, Lin JY (2015) The Oxford handbook of Africa and economics: Volume 1: context and concepts. Oxford University Press, New York, USA

Monti A, Romano MG (2010) Studi di fattibilità di progetti complessi. In: Mangiarotti A, Tronconi $\mathrm{O}$ (eds) Il progetto di fattibilità. Analisi tecnico-economica e sistemi costruttivi. McGraw-Hill, Milano (IT), pp 39-50

Ollivier T, Giraud PN (2011) Assessing sustainability, a comprehensive wealth accounting prospect: an application to Mozambique. Ecol Econ 70(3):503-512

PARPA (2011) International Monetary Fund "Republic of Mozambique: poverty reduction strategy paper", June 2011, IMF country report no. 11/132; https://www.imf.org/external/pubs/ft/scr/ 2011/cr11132.pdf

Porter A, Bohl D, Kwasi S, Donnenfeld Z, Cilliers J (2018) Prospects and challenges: Mozambique's growth and human development outlook to 2040. http://dx.doi.org/10.2139/ssrn.3099373

Scott J (2015) The risks of rapid urbanization in developing countries. https://www.zurich.com/en Thompson DA (2013) Constructing a history of independent Mozambique, 1974-1982: a study in photography. Kronos 39(1):158-184

UN-Habitat (United Nations Human Settlements Programme) (2015) Towards an African urban agenda. Nairobi, Kenya

UNICEF Mozambique, Water, sanitation \& hygiene. http://www.unicef.org.mz/en/our-work/whatwe-do/water-sanitation-hygiene/

WHO (World Health Organization) (2014) Mozambique. Urban health profile. http://www.who.int/ kobe_centre/measuring/urbanheart/mozambique.pdf

World Peace Foundation (2015) Mozambique: civil war. https://sites.tufts.edu/atrocityendings/ 2015/08/07/mozambique-civil-war/ 
Open Access This chapter is licensed under the terms of the Creative Commons Attribution 4.0 International License (http://creativecommons.org/licenses/by/4.0/), which permits use, sharing, adaptation, distribution and reproduction in any medium or format, as long as you give appropriate credit to the original author(s) and the source, provide a link to the Creative Commons license and indicate if changes were made.

The images or other third party material in this chapter are included in the chapter's Creative Commons license, unless indicated otherwise in a credit line to the material. If material is not included in the chapter's Creative Commons license and your intended use is not permitted by statutory regulation or exceeds the permitted use, you will need to obtain permission directly from the copyright holder.

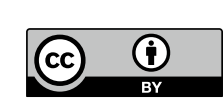

